\title{
Article \\ Short-Term Calorie Restriction Maintains Plasma Insulin Concentrations along with a Reduction in Hepatic Insulin-Degrading Enzyme Levels in db/db Mice
}

\author{
Yudai Nonaka ${ }^{1,2, *}$, Reo Takeda ${ }^{1}$, Yutaka Kano ${ }^{1}$ and Daisuke Hoshino ${ }^{1}$ \\ 1 Bioscience and Technology Program, Department of Engineering Science, University of \\ Electro-Communications, 1-5-1 Chofugaoka, Chofu, Tokyo 182-8585, Japan; takeda@ecc.pc.uec.ac.jp (R.T.); \\ kano@pc.uec.ac.jp (Y.K.); dhoshino@uec.ac.jp (D.H.) \\ 2 Japan Society for the Promotion of Science (JSPS), Kojimachi, Chiyoda-ku, Tokyo 102-0083, Japan \\ * Correspondence: y-nonaka02@hotmail.co.jp; Tel.: +81-42-443-5589
}

Citation: Nonaka, Y.; Takeda, R.; Kano, Y.; Hoshino, D. Short-Term Calorie Restriction Maintains Plasma Insulin Concentrations along with a Reduction in Hepatic

Insulin-Degrading Enzyme Levels in $\mathrm{db} / \mathrm{db}$ Mice. Nutrients 2021, 13, 1190. https://doi.org/10.3390/nu13041190

Academic Editor: Sara Baldassano

Received: 8 March 2021

Accepted: 29 March 2021

Published: 3 April 2021

Publisher's Note: MDPI stays neutra with regard to jurisdictional claims in published maps and institutional affiliations.

Copyright: (c) 2021 by the authors. Licensee MDPI, Basel, Switzerland. This article is an open access article distributed under the terms and conditions of the Creative Commons Attribution (CC BY) license (https:/ / creativecommons.org/licenses/by/ $4.0 /)$.

\begin{abstract}
Maintaining blood insulin levels is important for patients with diabetes because insulin secretion capacity declines with the development of the disease. Calorie restriction (CR) is effective for the improvement of glucose tolerance, but it is not clear whether CR can maintain insulin levels in the late stage of diabetes. We examined the effect of CR on whole-body glucose tolerance and fasting blood insulin concentrations in the late stage of diabetes. Male $\mathrm{db} / \mathrm{db}$ mice were subjected to either a standard laboratory diet ad libitum for 3 weeks (dbdb group) or $40 \% \mathrm{CR}$ (dbdb+CR group). CR significantly decreased body mass and epididymal fat weight. Glucose tolerance and fasting glucose levels were significantly improved with 3-week CR. Fasting insulin concentrations were decreased in the $\mathrm{dbdb}$ group but were maintained in the $\mathrm{dbdb}+\mathrm{CR}$ group. CR significantly reduced insulin-degrading enzyme (IDE) levels in the liver, and hepatic IDE levels were significantly positively and negatively correlated with plasma glucose concentrations (area under the curve) after glucose administration and after fasting insulin concentrations, respectively. Therefore, 3-week CR maintained blood insulin levels and improved glucose tolerance with decreased hepatic IDE levels in an animal model of late-stage diabetes.
\end{abstract}

Keywords: calorie restriction; glucose transporter 4 (GLUT-4); insulin-degrading enzyme (IDE); diabetes

\section{Introduction}

Type 2 diabetes mellitus (T2DM) increases the risk of hypertension and cardiovascular disease. The global epidemic of T2DM is a major public health problem. Disease progression is known to be caused by excessive fat accumulation. In fact, 60-90\% of all patients with T2DM are obese (body mass index (BMI) $\geq 30 \mathrm{~kg} / \mathrm{m}^{2}$ )) or overweight $\left(B M I \geq 25 \mathrm{~kg} / \mathrm{m}^{2}\right)$ [1]. The global epidemic of obesity can explain the dramatic elevation in the incidence and prevalence of T2DM. Excessive fat accumulation induces insulin resistance in peripheral tissue [2] and results in glucose intolerance [3,4]. In contrast, weight loss by gastric bypass decreases BMI, which is used as an indicator of obesity, and increases the whole-body glucose disposal rate [5]. Therefore, a decrease in fat accumulation can prevent and reverse the development of T2DM.

Calorie restriction (CR) is an efficacious dietary intervention to abrogate the accumulation of visceral fat. In fact, mild and/or moderate weight loss with a moderate decline in calorie intake is recommended for patients with T2DM [6]. It has been reported that $\sim 40 \%$ $\mathrm{CR}$ reduces body fat volume and fasting blood glucose and insulin levels and improves whole-body glucose tolerance in human [7,8] and animal experiments [9-11]. Fat reduction is associated with the CR-induced improvement of metabolism, but glucose uptake in peripheral tissue is also enhanced with CR. For example, CR leads to enhanced glucose transport with an increase in the levels of glucose transporter 4 (GLUT-4), which is a 
major transporter of glucose in skeletal muscle cells and in the cell surface membranes of insulin-stimulated muscle [12,13]. In addition, GLUT-4 levels in the adipose tissue have been reported to be important for maintaining whole-body glucose homeostasis [14-16]. Therefore, $\mathrm{CR}$ is an effective dietary intervention to prevent and ameliorate glucose intolerance due to its reduction in fat accumulation and improvement of glucose disposal and uptake in skeletal muscles and adipose tissues. The effect of CR on peripheral tissue has been studied, but the effect of CR on insulin levels, rather than on insulin action, has not been completely elucidated.

The pathophysiology of T2DM involves not only insulin resistance in peripheral tissue but also the impairment of insulin secretion capacity, particularly in the late stage of diabetes. As a consequence of long-term insulin resistance, the reduction in the number of functional $\beta$ cells leads to a deficiency in insulin secretion [17-19]. Insulin secretory capacity declines gradually with the progression of T2DM in human patients $[17,20]$. Most T2DM patients eventually require insulin therapy. Therefore, in the late stage of the disease, the maintenance of blood insulin levels is crucial in terms of therapy. As CR improves insulin secretion capacity in rats with obesity induced by intake of a high-fat diet [21], it is possible that $\mathrm{CR}$ prevents the reduction of blood insulin concentrations.

In the regulation of blood insulin levels, insulin-degrading enzyme (IDE) and carcinoembryonic antigen-related cell adhesion molecule 1 (CEACAM1), which promotes receptor-mediated insulin endocytosis and degradation in liver, also play a critical role [22] IDE expression is altered by various nutritional and physiological factors, such as exercise and dietary intervention $[23,24]$. Therefore, we hypothesized that CR maintains blood insulin levels in the late stage of diabetes with an elevation in insulin secretion and/or a reduction in IDE expression. To examine this hypothesis, we conducted this study to examine the effect of CR on whole-body glucose tolerance and blood insulin levels with its related proteins in the late stage of diabetes. We used mice with a mutation in the leptin receptor gene $(\mathrm{db} / \mathrm{db})$, which leads to insulin resistance in the early stage of T2DM, and deficiency of insulin secretion in the late stage of diabetes [25].

\section{Materials and Methods}

\subsection{Animal Treatment}

Nine-week-old male $\mathrm{db} / \mathrm{db}$ mice were housed individually under a 12:12-h light:dark cycle in a temperature-controlled room $\left(23^{\circ} \mathrm{C}\right)$. Mice were given a standard laboratory diet (CE-2; CLEA Japan, Tokyo, Japan) and water ad libitum. The mice were acclimated to the housing facility for 1 week. To examine the effects of CR on late-stage diabetes, we started CR intervention from 10 weeks old, as the previous study showed a decrease in blood insulin concentrations in $\mathrm{db} / \mathrm{db}$ mice at 10-12 weeks [25].

After the acclimation period, the mice were divided into two groups that matched their body weights, blood glucose concentrations, and food intake during the acclimation period: one group continued to receive the standard diet ad libitum for the entire 21-day experimental period ( $\mathrm{dbdb}$ group; $n=5$ ), and the second group received the standard diet equal to $60 \%$ of the average amount of food eaten by the $\mathrm{dbdb}$ group during the 21-day experimental period to decrease their body weight (dbdb+CR group; $n=5)$. Misty mice of the same age were obtained from Japan SLC and treated for the same period $(n=5)$. All mice were allowed to drink water freely during the 21-day dietary intervention. Body weight and the amount of food intake were recorded daily throughout the dietary intervention, and fasting plasma glucose levels were measured weekly after 4-h fasting (morning fasting, 06:00-10:00). The University of Electro-Communications Institutional Animal Care and Use Committee approved all animal experiments in this study (No. 31).

\subsection{Oral Glucose Tolerance Test}

The day before the oral glucose tolerance test (OGTT), the $\mathrm{dbdb}$ and $\mathrm{dbdb}+\mathrm{CR}$ groups had access to food ad libitum until 22:00 (food was removed after 22:00). After fasting for $12 \mathrm{~h}$, oral administration of glucose $(1 \mathrm{~g} / \mathrm{kg}$ body weight) was performed using a 
gavage needle with a ball tip. Blood was drawn from the tail vein and harvested in microhematocrit capillary tubes containing heparin (Thermo Fisher Scientific, Waltham, MA, USA) before and at 10, 30, 60, and 120 min after the glucose administration. After the samples were centrifuged at 10,000 rpm for $5 \mathrm{~min}$, the samples of plasma in the tubes were stored at $-80^{\circ} \mathrm{C}$ until analysis.

\subsection{Tissue Collection}

At the end of the experimental intervention, the mice were sacrificed under anesthesia using isoflurane without fasting. The tibial anterior (TA) muscle and liver were harvested and weighed. Then, the epididymal fat was harvested and weighed. We focused on epididymal fat because the weights are positively correlated with glucose concentrations during glucose tolerance test [26]. Liver, muscle, and fat samples were frozen at $-80^{\circ} \mathrm{C}$ until analysis.

Mice fasted for $4 \mathrm{~h}$ (morning fasting) before the blood glucose and insulin measurements at 10 and 13 weeks. Blood samples were drawn from the tail vein and harvested into micro-hematocrit capillary tubes covered with heparin (Thermo Fisher Scientific, Waltham, MA, USA). Plasma samples were separated by centrifugation at 10,000 rpm for $5 \mathrm{~min}$ and were stored at $-80^{\circ} \mathrm{C}$ until analysis.

\subsection{Plasma Glucose and Insulin Concentrations}

Concentrations of plasma glucose and insulin were measured using the Glucose C2 Test Wako Kit (Fujifilm Wako Pure Chemical Co., Osaka, Japan) and the Mouse Insulin ELISA Kit (Mercodia AB, Uppsala, Sweden), respectively.

\subsection{Tissue Homogenization}

Frozen TA muscle, epididymal fat, and liver were homogenized in an ice-cold RIPA lysis buffer (EMD Millipore, Temecula, CA) containing $0.25 \%$ deoxycholic acid, $50 \mathrm{mM}$ Tris$\mathrm{HCl}, 150 \mathrm{mM} \mathrm{NaCl}, 1 \%$ NP-40, 1 mM EDTA (pH 7.4), phosphatase inhibitors (PhosSTOP; Roche, Basel, Switzerland), and a protease inhibitor cocktail (Sigma-Aldrich, St. Louis, MO, USA). The homogenates were subjected to 3 freeze-thaw cycles to destroy intracellular organelles and rotated continuously at $4{ }^{\circ} \mathrm{C}$ for $60 \mathrm{~min}$ to solubilize the protein. The homogenized tissue samples were centrifuged at $700 \times g$ for $5 \mathrm{~min}$ at $4{ }^{\circ} \mathrm{C}$, and the supernatants were harvested. Total protein content per tissue was quantified with a BCA Protein Assay Kit (Pierce, Rockford, IL, USA).

\subsection{Western Blotting}

The samples were mixed with sample buffer (Thermo Fisher Scientific, Waltham, MA, USA) and heated for $5 \mathrm{~min}$ in a heating block at $95^{\circ} \mathrm{C}$. Sample protein was loaded onto gels in equal amounts, separated by sodium dodecyl sulfate-polyacrylamide gel electrophoresis ( $7.5 \%$ or $10 \%$ resolving gels), and transferred to polyvinylidene difluoride (PVDF) membranes at $200 \mathrm{~mA}$ for $90 \mathrm{~min}$. The membranes were then blocked for $1 \mathrm{~h}$ at room temperature in Tris-buffered saline with $0.1 \%$ Tween 20 (TBS-T; $137 \mathrm{mM} \mathrm{NaCl}$, $20 \mathrm{mM}$ Tris base, $\mathrm{pH}$ 7.6) containing $5 \%(w / v)$ nonfat powdered milk for $5 \mathrm{~min}$ at room temperature in Bullet Blocking One solution (Nacalai Tesque, Kyoto, Japan). The membranes were incubated overnight at $4{ }^{\circ} \mathrm{C}$ with the specific primary antibody diluted 1:1000 in TBS-T containing $5 \%$ bovine serum albumin. The primary antibodies used were anti-IDE (sc-393887; Santa Cruz Biotechnology, Dallas, TX, USA), anti-CD66a (carcino-embryonic antigen-related cell adhesion molecule 1 (CEACAM1); 14-0661-80; Invitrogen, Carlsbad, CA, USA), and anti-GLUT-4 (ab33780; Abcam, Cambridge, UK). After incubation with the specific antibody, the membranes were incubated for $1 \mathrm{~h}$ at room temperature with secondary antibodies (anti-mouse IgG, NA931 or anti-rabbit IgG, NA9340; Cytiva, Marlborough, MA, USA) and diluted 1:5000 in TBS-T containing 1\% nonfat powdered milk. Bands were visualized by the Chemi-Lumi One Reagent (Nacalai Tesque, Kyoto, Japan) and 
quantified by Image Studio (LI-COR, Lincoln, NE, USA). Ponceau staining was performed to verify equal loading of samples.

\subsection{Glucose-Stimulated Insulin Secretion of Isolated Islets}

Another set of $\mathrm{db} / \mathrm{db}$ mice (each group $n=5$ ) was subjected to CR as described above, their islets were isolated, and glucose-stimulated insulin secretion was measured. As described previously [27], the islets were isolated by a method for collagenase digestion of the pancreas from euthanized mice. The mice were sacrificed after the dietary intervention, and the common bile duct was cannulated using a needle (Natsume Seisakusho, Tokyo, Japan). Then, Dulbecco's modified Eagle's medium ( $2-3 \mathrm{~mL}$ ) containing $2 \mathrm{mg} / \mathrm{mL}$ collagenase IV (GIBCO, Carlsbad, CA, USA) was injected into the pancreas, and the pancreas was removed from the surrounding tissues. The removed pancreas was incubated in the solution for $35 \mathrm{~min}$ at $37^{\circ} \mathrm{C}$ for tissue digestion. The digested tissue was washed twice with RPMI-1640 medium. Five size-matched islets were incubated for $30 \mathrm{~min}$ in $300 \mathrm{uL}$ Krebs-Ringer buffer ( $15 \mathrm{mM}$ HEPES pH 7.4, $2 \mathrm{mM} \mathrm{CaCl}_{2}, 5 \mathrm{mM} \mathrm{KCl}, 1 \mathrm{mM} \mathrm{MgCl} 2,120 \mathrm{mM}$ $\mathrm{NaCl}, 24 \mathrm{mM} \mathrm{NaHCO}, 0.1 \%$ bovine serum albumin, and $2.8 \mathrm{mM}$ glucose). After the incubation, the isolated islets were stimulated with high or low glucose, during which the islets were incubated for $60 \mathrm{~min}$ with $16.7 \mathrm{mM}$ high-glucose Krebs-Ringer buffer or $2.8 \mathrm{mM}$ low-glucose Krebs-Ringer buffer, respectively. The insulin concentration in the buffer containing the islets was measured using a Mouse Insulin ELISA Kit (Mercodia AB, Uppsala, Sweden).

\subsection{Statistical Analysis}

Data are represented as the mean \pm standard error of the mean (SEM). For the data of the OGTT, a two-way analysis of variance (Prism ver.8 Software; GraphPad, San Diego, CA, USA) was used to test the effects of time and $\mathrm{CR}$ in $\mathrm{db} / \mathrm{db}$ mice. For the other experiments, Student's $t$-test was used to test statistical differences between the values obtained from the $\mathrm{dbdb}$ and $\mathrm{dbdb}+\mathrm{CR}$ groups. Pearson's correlation coefficient was used for correlation analysis. Statistical significance was set at a $p$-value of $<0.05$.

\section{Results}

\subsection{Body Weight, Epididymal Fat Weight, and Total Food Intake}

Changes in body weight during the 3-week dietary intervention are shown in Figure 1. During the intervention period, daily $C R$ in the $d b d b+C R$ group for 3 weeks induced a substantial decrease in body weight. The final body weight was approximately $14 \%$ lower in the $\mathrm{dbdb}+\mathrm{CR}$ group than in the $\mathrm{dbdb}$ group $(p<0.01$; Table 1$)$. Total food intake during the 3-week experimental period was $\sim 40 \%$ lower in the $\mathrm{dbdb}+\mathrm{CR}$ group than in the $\mathrm{dbdb}$ group $(p<0.001$; Table 1$)$. Liver weight and epididymal fat weight were also lower in the $\mathrm{dbdb}+\mathrm{CR}$ group than in the dbdb group (liver weight: $p<0.01$; epididymal fat weight: $p<0.05$; Table 1 ).

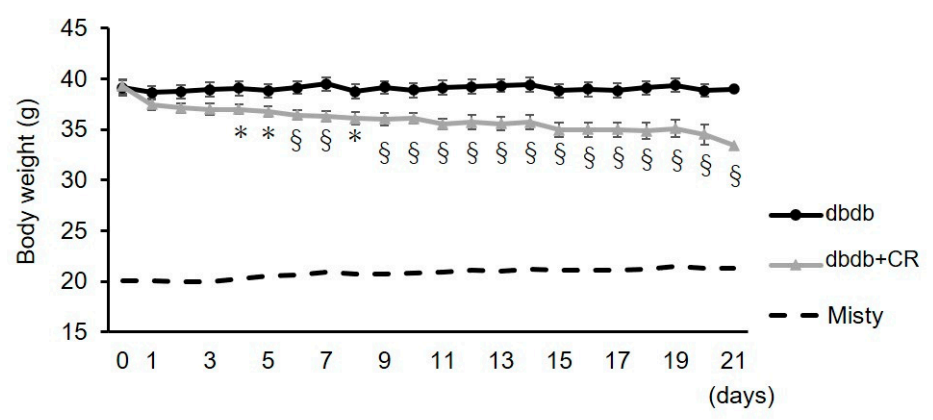

Figure 1. Changes in the body weight of rats during a 21-day dietary intervention. dbdb, ad libitum-fed control group; $\mathrm{dbdb}+\mathrm{CR}$, daily calorie restriction group. Data of misty mice were used as reference values (dotted lines). Data are the mean $\pm \operatorname{SEM}(n=5) .{ }^{*} p<0.05, \S p<0.01$ compared with the $\mathrm{dbdb}$ group. 
Table 1. Body weight, total food intake, liver weight, epididymal fat weight, and concentrations of plasma glucose and insulin in mice.

\begin{tabular}{|c|c|c|c|}
\hline & $\mathrm{dbdb}$ & $\mathrm{dbdb}+\mathrm{CR}$ & Misty \\
\hline Initial body weight $(\mathrm{g})$ & $39.1 \pm 0.7$ & $39.2 \pm 0.7$ & $20.0 \pm 0.3$ \\
\hline Final body weight (g) & $39.0 \pm 0.7$ & $33.4 \pm 0.9^{* *}$ & $21.2 \pm 0.2$ \\
\hline Total food intake $(\mathrm{g})$ & $107 \pm 4$ & $64 \pm 1 * * *$ & $72 \pm 1$ \\
\hline Liver weight $(\mathrm{g})$ & $2.1 \pm 0.1$ & $1.9 \pm 0.1^{* *}$ & $1.3 \pm 0.1$ \\
\hline Epidydimal fat weight $(\mathrm{g})$ & $1.7 \pm 0.1$ & $1.5 \pm 0.1 *$ & $0.3 \pm 0.1$ \\
\hline Plasma glucose concentration (10 weeks) (mg/dL) & $672 \pm 18$ & $644 \pm 67$ & $167 \pm 7$ \\
\hline Plasma glucose concentration (13 weeks) (mg/dL) & $759 \pm 34$ & $599 \pm 24 *$ & $199 \pm 6$ \\
\hline$\Delta$ Plasma glucose concentration (13 vs. 10 weeks) $(\mathrm{mg} / \mathrm{dL})$ & $87 \pm 28$ & $-45 \pm 36 *$ & $32 \pm 7$ \\
\hline Plasma insulin concentration (10 weeks) $(\mu \mathrm{g} / \mathrm{L})$ & $8.2 \pm 1.7$ & $9.5 \pm 2.5$ & $0.5 \pm 0.1$ \\
\hline Plasma insulin concentration ( 13 weeks) $(\mu \mathrm{g} / \mathrm{L})$ & $4.4 \pm 0.6$ & $11.6 \pm 4.0$ & $0.3 \pm 0.1$ \\
\hline$\Delta$ Plasma insulin concentration $(13$ vs. 10 weeks $)(\mu \mathrm{g} / \mathrm{L})$ & $-3.7 \pm 1.8$ & $2.1 \pm 1.7^{*}$ & $-0.2 \pm 0.1$ \\
\hline
\end{tabular}

Data are the mean \pm SEM, $n=5 .{ }^{*} p<0.05,{ }^{* *} p<0.01$, and ${ }^{* * *} p<0.001$, compared with the dbdb group. The mice fasted for $4 \mathrm{~h}$ for measurement of blood glucose and insulin concentration. $\mathrm{dbdb}$, ad libitum-fed control group; $\mathrm{dbdb}+\mathrm{CR}$, daily calorie restriction group.

\subsection{Fasting Plasma Glucose and Insulin Concentrations}

At the completion of the 21-day dietary intervention, fasting plasma glucose concentrations were lower in the $\mathrm{dbdb}+\mathrm{CR}$ group than in the $\mathrm{dbdb}$ group $(p<0.05$; Table 1$)$. Although there was no significant difference in fasting plasma insulin concentrations between both groups (Table 1), there was a significant difference in the change in fasting blood glucose and insulin concentrations between the two groups (both $p<0.05$; Table 1 ).

\subsection{OGTT}

To test the effects of CR on whole-body glucose tolerance, we conducted an OGTT. The mice in the $\mathrm{dbdb}$ group became more hyperglycemic than those of the $\mathrm{dbdb}+\mathrm{CR}$ group in response to glucose administration (Figure 2). The elevation in plasma glucose concentrations was lower in the $\mathrm{dbdb}+\mathrm{CR}$ group than in the $\mathrm{dbdb}$ group at 10 and $120 \mathrm{~min}$ after glucose injection (10 min: $p<0.05 ; 120$ min: $p<0.05$; Figure 2). Plasma insulin concentrations did not significantly differ between the two groups.
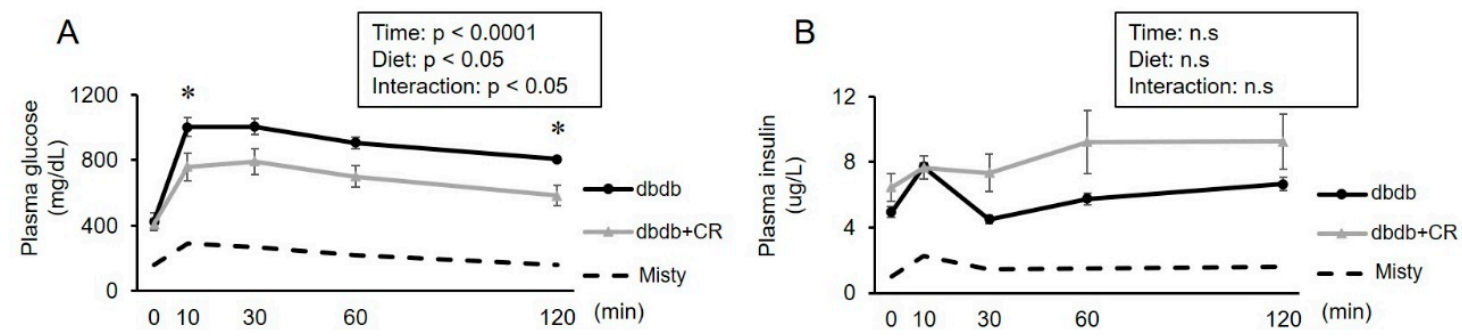

Figure 2. Effects of calorie restriction on glucose tolerance in $\mathrm{db} / \mathrm{db}$ mice. Plasma glucose $(\mathbf{A})$ and insulin (B) concentrations after oral glucose administration. $\mathrm{dbdb}, \mathrm{db} / \mathrm{db}$ ad libitum-fed control group; $\mathrm{dbdb}+\mathrm{CR}$, daily calorie restriction group. Data of misty mice were used as reference values (dotted lines). Data are the mean $\pm \operatorname{SEM}(n=5) .{ }^{*} p<0.05$ compared with the $\mathrm{dbdb}$ group.

\subsection{GLUT-4 Protein Levels in TA Muscle and Epididymal Adipose Tissue}

GLUT-4 protein levels in epididymal adipose tissue, but not TA muscle, were significantly higher in the $\mathrm{dbdb}+\mathrm{CR}$ group than in the $\mathrm{dbdb}$ group $(p<0.05$; Figure 3$)$. 

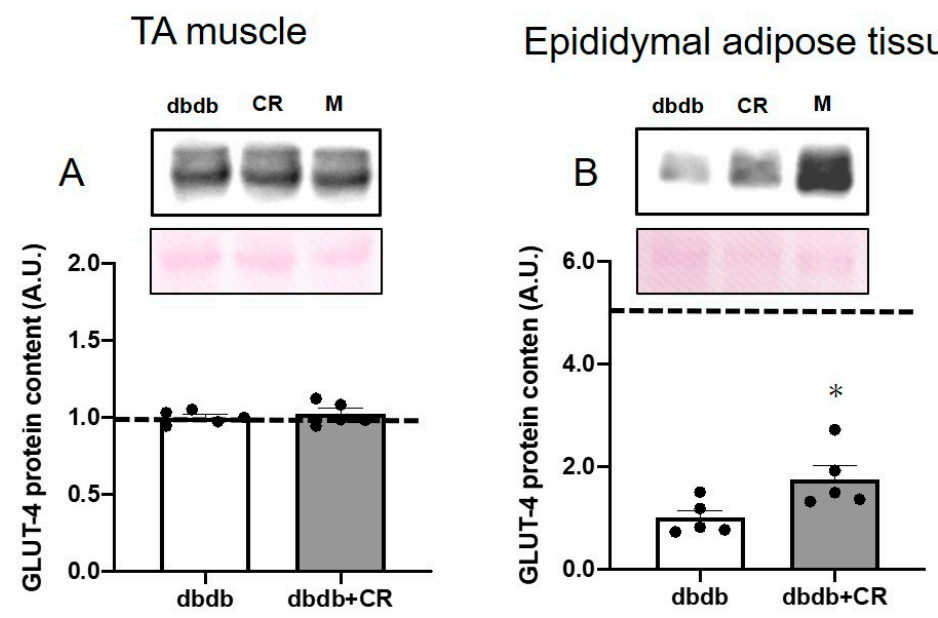

Figure 3. Effects of calorie restriction on GLUT-4 levels in $\mathrm{db} / \mathrm{db}$ mice. GLUT-4 protein levels in mouse TA (tibialis anterior) muscle (A) and epididymal adipose tissue (B). dbdb, ad libitum-fed control group; $\mathrm{dbdb}+\mathrm{CR}$, daily calorie restriction group. Data of misty mice were used as reference values (dotted lines). Data are the mean $\pm \operatorname{SEM}(n=5) .{ }^{*} p<0.05$ compared with the dbdb group.

\subsection{Glucose-Stimulated Insulin Secretion in Isolated Islets}

After the 3-week intervention period, pancreatic islets isolated from the mice in both groups were used for the measurement of glucose-stimulated insulin secretion. Insulin secretion in response to low-glucose treatment (baseline, $2.8 \mathrm{mM}$ glucose) was lower in the $\mathrm{dbdb}+\mathrm{CR}$ group than in the $\mathrm{dbdb}$ group $(p<0.05$; Figure 4$)$. Insulin secretion in response to high-glucose stimulation (16.7 mM glucose) did not differ between groups.

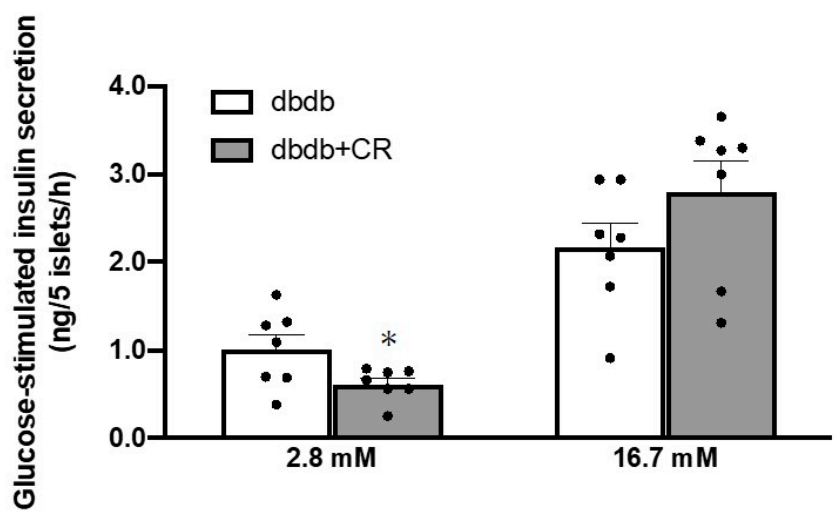

Figure 4. Effects of calorie restriction on glucose-stimulated insulin secretion in $\mathrm{db} / \mathrm{db}$ mice. $\mathrm{dbdb}$, ad libitum-fed control group; $\mathrm{dbdb}+\mathrm{CR}$, daily calorie restriction group. Data of misty mice were used as reference values (dotted lines). Data are the mean $\pm \operatorname{SEM}(n=7) .{ }^{*} p<0.05$ compared with the $\mathrm{dbdb}$ group.

\subsection{IDE Protein Levels in TA Muscle and Liver and CEACAM1 Protein Levels in Liver}

We explored the mechanism by which fasting insulin concentrations were maintained with the CR intervention. While there were no significant differences in IDE protein expression in the TA muscle and CEACAM1 levels in the liver between the two groups, the hepatic IDE protein levels were lower in the $\mathrm{dbdb}+\mathrm{CR}$ group than in the dbdb group $(p<0.05$; Figure 5). Hepatic IDE protein levels were positively correlated with fasting glucose concentrations ( $r=0.655, p<0.05$; Figure 6). Hepatic IDE levels were negatively correlated with concentrations of plasma insulin $(r=0.718, p<0.05$; Figure 6$)$. In addition, hepatic IDE protein levels were significantly correlated with the plasma glucose area under the curve (AUC) during the OGTT $(r=0.654, p<0.05$; Figure 6). 

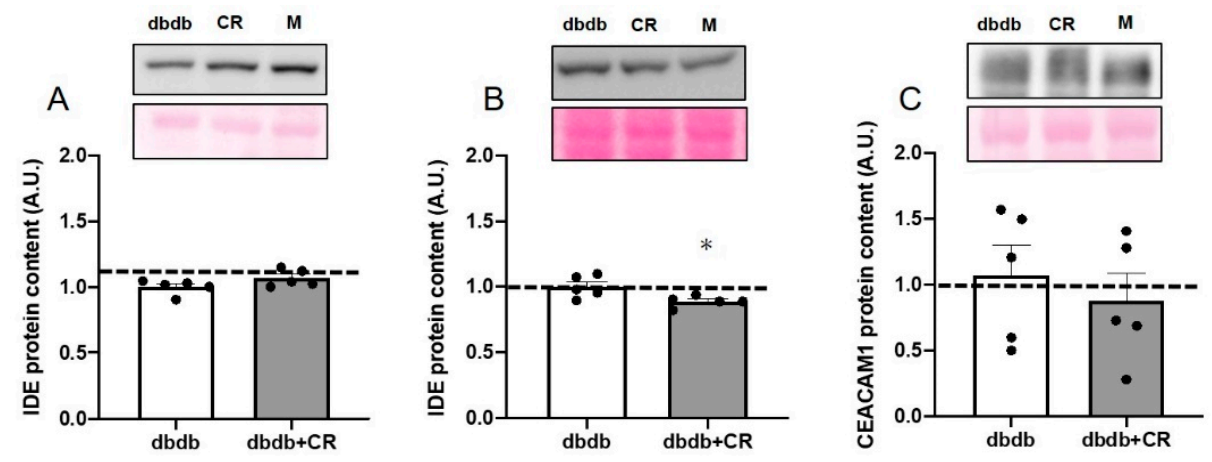

Figure 5. Effects of calorie restriction on insulin-degrading enzyme (IDE) and carcino-embryonic antigen-related cell adhesion molecule 1 (CEACAM1) levels in $\mathrm{db} / \mathrm{db}$ mice. IDE protein levels in mouse tibialis anterior muscle (A) and liver (B) and CEACAM1 protein levels in liver (C). dbdb, ad libitum-fed control group; $\mathrm{dbdb}+\mathrm{CR}$, daily calorie restriction group. Data of misty mice were used as reference values (dotted lines). Data are the mean $\pm \operatorname{SEM}(n=5) .{ }^{*} p<0.05$ compared with the $\mathrm{dbdb}$ group.

A

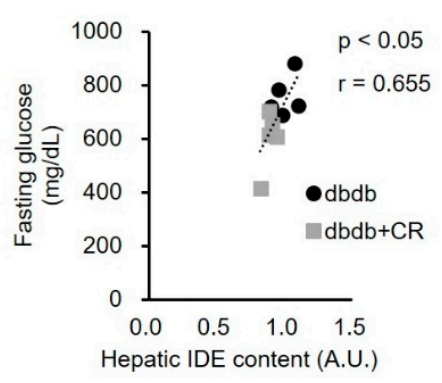

B

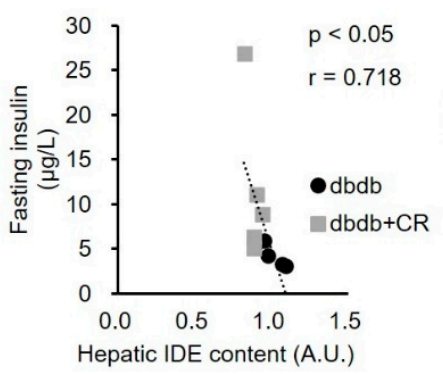

C

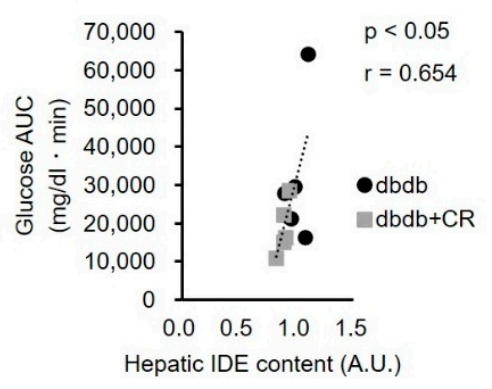

Figure 6. Correlations between hepatic insulin-degrading enzyme (IDE) levels and fasting glucose (A) or fasting insulin (B) concentrations or glucose area under the curve (AUC) during the oral glucose tolerance test (OGTT) (C). dbdb, ad libitum-fed control group; $\mathrm{dbdb}+\mathrm{CR}$, daily calorie restriction group.

\section{Discussion}

Our study was conducted to examine the effects of 3-week CR on glucose tolerance and fasting insulin concentrations in the late stage of diabetes. We discovered that 3-week $\mathrm{CR}$ in $\mathrm{db} / \mathrm{db}$ mice improved glucose tolerance, with a decline in epididymal adipose tissue and an increase in fat GLUT-4 levels, and maintained fasting insulin concentrations, accompanied by decreased IDE levels in the liver.

Three-week CR improved glucose tolerance, such as lowered plasma glucose concentrations during the OGTT (Figure 2A). The CR-induced improvement of glucose tolerance in $\mathrm{db} / \mathrm{db}$ mice was consistent with the results of previous studies that investigated the effects of CR on glycemic improvement and glucose metabolism [10,11,21]. As insulin concentrations during the OGTT did not differ between the two groups (Figure 2A), we estimated that the reason for the improvement in the OGTT was also the reason for the increase in glucose uptake in peripheral tissue. However, there was no significant change in GLUT-4 levels, a major glucose transporter in skeletal muscle cells [28], with 3-week CR (Figure 3A). We did not measure the parameters of insulin sensitivity of skeletal muscle, but previous studies reported that CR increased GLUT-4 levels in the cell surface membranes of insulin-stimulated muscle [12] without a change in total GLUT-4 protein expression [13]. It is likely that insulin sensitivity was improved by 3-week CR without changes in total GLUT-4 levels. The GLUT-4 protein in adipose tissue is also associated with whole-body insulin resistance $[15,29]$. Interestingly, CR significantly up-regulated GLUT-4 protein levels in adipose tissue (Figure 3B). This increase in GLUT-4 content in epididymal adipose 
tissue would contribute, in part, to the improvement of whole-body glucose tolerance, because previous studies reported that diabetes decreases adipose GLUT-4 expression and impairs glucose tolerance [29] and revealed that quantitative alterations of adipose GLUT-4 levels alter whole-body glucose tolerance, such as skeletal muscle insulin resistance in transgenic mice $[14,15,30]$. Furthermore, since adipose tissue accounts for $\sim 10 \%$ of the insulin-stimulated whole-body glucose uptake [16], an increase in GLUT-4 protein levels after the CR intervention would contribute, in part, to the improvement of insulin-stimulated glucose uptake into the adipose tissue. In addition, CR induced an approximately 10\% reduction in epidydimal fat weight in the present study (Table 1). Since excessive fat accumulation aggravates insulin sensitivity in peripheral tissue [3,4], the CR-induced reduction in adipose tissue weight may also be implicated in the improvement of insulin sensitivity in skeletal muscle and adipose tissue. Therefore, these data suggest that the CR-induced improvement of glucose tolerance during the OGTT was associated with an increase in adipose GLUT-4 levels and a reduction in epididymal adipose tissue weight.

Fasting insulin concentrations decreased from 10 to 13 weeks of age in the dbdb group, but they were maintained in the $\mathrm{dbdb}+\mathrm{CR}$ group (Table 1 ), indicating that $\mathrm{CR}$ can inhibit the reduction of fasting blood insulin concentrations shown in the late stage of diabetes. To clarify whether this maintenance of fasting plasma insulin concentrations was due to alternations in insulin secretion and/or degradation, we measured insulin secretion rates in extracted islets and the levels of IDE protein. Insulin secretion in response to low-glucose stimulation, but not high-glucose, was significantly lower in the $\mathrm{dbdb}+\mathrm{CR}$ group than in the dbdb group (Figure 4). This result is comparable with the results of a previous study in which insulin secretion in response to low-glucose stimulation $(2.8 \mathrm{mM})$ was reduced after 3week CR [21]. Therefore, we consider that insulin degradation, rather than insulin secretion, may have played a role in the maintenance of fasting blood insulin concentrations in the CR group in this study. In fact, 3-week CR significantly decreased IDE expression levels in the liver but did not change hepatic CEACAM1 or muscle IDE expression levels (Figure 5). Furthermore, there was a significant negative correlation between IDE expression in the liver and fasting insulin concentrations in the blood (Figure 6B). This relationship suggests that the reduction in IDE expression contributes to the inhibition of insulin deficiency in the late stage of diabetes. This is supported by previous studies in which short-term IDE knockout can increase fasting insulin levels [31,32]. Taken together, these results suggest that short-term CR in the late stage of diabetes, with decreases in blood insulin levels, can help to maintain blood insulin levels, potentially by reducing IDE levels.

Insulin sensitivity in peripheral tissue and insulin secretion from $\beta$ cells in the pancreas are considered important for glucose disposal [33]. Our study provides the novel finding that a decrease in IDE can improve glucose disposal in the late stage of diabetes. This is because a significant positive correlation was shown between IDE levels in the liver and fasting glucose concentrations or glucose AUC during an OGTT (Figure 6C). However, previous studies reported that IDE levels had a positive effect on glucose tolerance [34,35]. For example, whole-body and liver-specific knockout of IDE impairs fasting glucose levels and glucose tolerance [32,36,37]. An exercise-induced increase in IDE expression was shown to reduce glycemia and improve insulin sensitivity in mice [24]. We consider that the differences in the results between previous studies and ours are because we used a late-stage model of diabetes, while previous studies used healthy animals. The resulting decrease in IDE levels in the present study may represent a specific effect of CR in late-stage diabetes. In fact, there was no positive relationship between IDE levels and fasting glucose concentrations or glucose AUC during the OGTT when correlations were analyzed in this study, including for the healthy controls. A previous study also found that the effects of a dipeptidyl peptidase-IV inhibitor on plasma insulin concentrations were different between late- and early-stage models of diabetes [38]. In end-stage diabetes, in which blood insulin concentrations are lowered, the adaptation to $\mathrm{CR}$ or other pharmacological and nutritional interventions is partially different from that observed in healthy subjects. Therefore, as the 
practical significance of this study, the CR-induced reduction in IDE expression would be a useful therapeutic intervention for patients in the late stage of diabetes.

This study has several limitations. It is not clear whether insulin concentration is maintained in late-stage human patients when their hepatic IDE protein levels are decreased. Furthermore, we need to examine sex differences in effects of $C R$ in late-stage of the disease because we used only male mice and there are differences between male and female mice in health and longevity benefits with CR [39]. In this study, Mice performed $12 \mathrm{~h}$ fasting and $4 \mathrm{~h}$ fasting before the measurements of blood glucose and insulin concentrations. Fasting itself may induce CR effects but they would be little because 3-day CR ( $40 \%$ CR) did not alter glucose tolerance but 10-day CR induced improvement of glucose tolerance [10]. We need to clarify these issues in the future study.

In conclusion, short-term CR in an animal model of late-stage diabetes increased adipose tissue GLUT-4 levels and reduced epididymal adipose tissue weight, leading to an improvement in whole-body glucose tolerance. The CR-induced improvement in blood glucose concentrations was associated with the maintenance of fasting blood insulin levels and decreased IDE expression in the liver.

Author Contributions: Y.N. and R.T. performed the experiments. Y.N., Y.K., and D.H. contributed to the conception and experimental design, data analyses, interpretation of the findings, and preparation of the manuscript. All authors have read and agreed to the published version of the manuscript.

Funding: This study was supported by the Grant-in-Aid for JSPS Research Fellows (18J02090).

Institutional Review Board Statement: The study was approved by the Institutional Review Board of the Animal Experimental Committee of the University of Electro-Communication (No. 31).

Data Availability Statement: The data presented in this study are available on request from the corresponding author.

Conflicts of Interest: All authors declare no conflict of interest.

\section{References}

1. Siddiqui, S. Obesity and diabetes: Interrelationship. Adv. Obes. Weight Manag. Control 2018, 8, 155-158. [CrossRef]

2. Kim, J.Y.; Nolte, L.A.; Hansen, P.A.; Han, D.-H.; Ferguson, K.; Thompson, P.A.; Holloszy, J.O. High-fat diet-induced muscle insulin resistance: Relationship to visceral fat mass. Am. J. Physiol. Integr. Comp. Physiol. 2000, 279, R2057-R2065. [CrossRef] [PubMed]

3. Katsuki, A.; Sumida, Y.; Urakawa, H.; Gabazza, E.C.; Murashima, S.; Maruyama, N.; Morioka, K.; Nakatani, K.; Yano, Y.; Adachi, Y. Increased visceral fat and serum levels of triglyceride are associated with insulin resistance in Japanese metabolically obese, normal weight subjects with normal glucose tolerance. Diabetes Care 2003, 26, 2341-2344. [CrossRef]

4. Koska, J.; Stefan, N.; Permana, P.A.; Weyer, C.; Sonoda, M.; Bogardus, C.; Smith, S.R.; Joanisse, D.R.; Funahashi, T.; Krakoff, J.; et al. Increased fat accumulation in liver may link insulin resistance with subcutaneous abdominal adipocyte enlargement, visceral adiposity, and hypoadiponectinemia in obese individuals. Am. J. Clin. Nutr. 2008, 87, 295-302. [CrossRef] [PubMed]

5. Friedman, J.E.; Dohm, G.L.; Leggett-Frazier, N.; Elton, C.W.; Tapscott, E.B.; Pories, W.P.; Caro, J.F. Restoration of insulin responsiveness in skeletal muscle of morbidly obese patients after weight loss: Effect on muscle glucose transport and glucose transporter GLUT4. J. Clin. Invest. 1992, 89, 701-705. [CrossRef] [PubMed]

6. American Diabetes Association. Nutrition recommendations and principles for people with diabetes mellitus. Diabetes Care 1994, 17, 519-522. [CrossRef]

7. Petersen, K.F.; Dufour, S.; Morino, K.; Yoo, P.S.; Cline, G.W.; Shulman, G.I. Reversal of muscle insulin resistance by weight reduction in young, lean, insulin-resistant offspring of parents with type 2 diabetes. Proc. Natl. Acad. Sci. USA 2012, 109, 8236-8240. [CrossRef]

8. Weiss, E.P.; Jordan, R.C.; Frese, E.M.; Albert, S.G.; Villareal, D.T.; Weiss, A.; Jordan, R.C.; Frese, E.M.; Albert, S.G.; Villareal, D.T. Effects of Weight Loss on Lean Mass, Strength, Bone, and Aerobic Capacity. Med. Sci. Sport Exerc. 2017, 49, 206-217. [CrossRef]

9. Marchal, J.; Blanc, S.; Epelbaum, J.; Aujard, F.; Pifferi, F. Effects of chronic calorie restriction or dietary resveratrol supplementation on insulin sensitivity markers in a primate, Microcebus murinus. PLoS ONE 2012, 7, e34289. [CrossRef]

10. Matyi, S.; Jackson, J.; Garrett, K.; Deepa, S.S.; Unnikrishnan, A. The effect of different levels of dietary restriction on glucose homeostasis and metabolic memory. GeroScience 2018, 40, 139-149. [CrossRef]

11. Wei, S.; Zhao, J.; Bai, M.; Li, C.; Zhang, L.; Chen, Y. Comparison of glycemic improvement between intermittent calorie restriction and continuous calorie restriction in diabetic mice. Nutr. Metab. 2019, 16, 60. [CrossRef] 
12. Dean, D.J.; Brozinick, J.T.; Cushman, S.W.; Cartee, G.D. Calorie restriction increases cell surface GLUT-4 in insulin-stimulated skeletal muscle. Am. J. Physiol. 1998, 275, E957-E964. [CrossRef] [PubMed]

13. Sequea, D.A.; Sharma, N.; Arias, E.B.; Cartee, G.D. Calorie restriction enhances insulin-stimulated glucose uptake and akt phosphorylation in both fast-twitch and slow-twitch skeletal muscle of 24-month-old rats. J. Gerontol. Ser. A Biol. Sci. Med. Sci. 2012, 67, 1279-1285. [CrossRef] [PubMed]

14. Shepherd, P.R.; Gnudi, L.; Tozzo, E.; Yang, H.; Leach, F.; Kahn, B.B. Adipose cell hyperplasia and enhanced glucose disposal in transgenic mice overexpressing GLUT4 selectively in adipose tissue. J. Biol. Chem. 1993, 268, 22243-22246. [CrossRef]

15. Abel, E.D.; Peroni, O.; Kim, J.K.; Kim, Y.B.; Boss, O.; Hadro, E.; Minnemann, T.; Shulman, G.I.; Kahn, B.B. Adipose-selective targeting of the GLUT4 gene impairs insulin action in muscle and liver. Nature 2001, 409, 729-733. [CrossRef]

16. Smith, U. Impaired ('diabetic') insulin signaling and action occur in fat cells long before glucose intolerance-Is insulin resistance initiated in the adipose tissue? Int. J. Obes. 2002, 26, 897-904. [CrossRef]

17. King, B.C.; Blom, A.M. Non-traditional roles of complement in type 2 diabetes: Metabolism, insulin secretion and homeostasis. Mol. Immunol. 2017, 84, 34-42. [CrossRef]

18. Cnop, M.; Welsh, N.; Jonas, J.C.; Jörns, A.; Lenzen, S.; Eizirik, D.L. Mechanisms of pancreatic $\beta$-cell death in type 1 and type 2 diabetes: Many differences, few similarities. Diabetes 2005, 54, S97-S107. [CrossRef] [PubMed]

19. Dor, Y.; Glaser, B. Beta-Cell Dedifferentiation and Type 2 Diabetes. N. Engl. J. Med. 2013, 368, 572-573. [CrossRef]

20. Guillausseau, P.J.; Meas, T.; Virally, M.; Laloi-Michelin, M.; Médeau, V.; Kevorkian, J.P. Abnormalities in insulin secretion in type 2 diabetes mellitus. Diabetes Metab. 2008, 34, S43-S48. [CrossRef]

21. Gao, X.; Yan, D.; Zhao, Y.; Tao, H.; Zhou, Y. Moderate calorie restriction to achieve normal weight reverses $\beta$-cell dysfunction in diet-induced obese mice: Involvement of autophagy. Nutr. Metab. 2015, 12, 34. [CrossRef]

22. Najjar, S.M.; Perdomo, G. Hepatic Insulin Clearance: Mechanism and Physiology. Physiology (Bethesda) 2019, 34, 198-215. [CrossRef] [PubMed]

23. Rezende, L.F.; Camargo, R.L.; Branco, R.C.S.; Cappelli, A.P.G.; Boschero, A.C.; Carneiro, E.M. Reduced insulin clearance and lower insulin-degrading enzyme expression in the liver might contribute to the thrifty phenotype of protein-restricted mice. $B r$. $J$. Nutr. 2014, 112, 900-907. [CrossRef]

24. Kurauti, M.A.; Freitas-Dias, R.; Ferreira, S.M.; Vettorazzi, J.F.; Nardelli, T.R.; Araujo, H.N.; Santos, G.J.; Carneiro, E.M.; Boschero, A.C.; Rezende, L.F.; et al. Acute Exercise Improves Insulin Clearance and Increases the Expression of Insulin-Degrading Enzyme in the Liver and Skeletal Muscle of Swiss Mice. PLoS ONE 2016, 11, e0160239. [CrossRef]

25. Cheng, C.-W.; Villani, V.; Buono, R.; Wei, M.; Kumar, S.; Yilmaz, O.H.; Cohen, P.; Sneddon, J.B.; Perin, L.; Longo, V.D. FastingMimicking Diet Promotes Ngn3-Driven $\beta$-Cell Regeneration to Reverse Diabetes. Cell 2017, 168, 775-788. [CrossRef]

26. Castaño, C.; Kalko, S.; Novials, A.; Párrizas, M. Obesity-associated exosomal miRNAs modulate glucose and lipid metabolism in mice. Proc. Natl. Acad. Sci. USA 2018, 115, 12158-12163. [CrossRef] [PubMed]

27. Nonaka, Y.; Takeda, R.; Kano, Y.; Hoshino, D. Effects of acute 3-h swimming exercise on insulin secretion capacity of pancreatic islets. J. Phys. Fit. Sport. Med. 2020, 9, 173-179. [CrossRef]

28. Kawanaka, K.; Tabata, I.; Katsuta, S.; Higuchi, M. Changes in insulin-stimulated glucose transport and GLUT-4 protein in rat skeletal muscle after training. J. Appl. Physiol. 1997, 83, 2043-2047. [CrossRef]

29. Park, S.Y.; Choi, G.H.; Choi, H.I.; Ryu, J.; Jung, C.Y.; Lee, W. Calorie restriction improves whole-body glucose disposal and insulin resistance in association with the increased adipocyte-specific GLUT4 expression in Otsuka Long-Evans Tokushima Fatty rats. Arch. Biochem. Biophys. 2005, 436, 276-284. [CrossRef] [PubMed]

30. Tozzo, E.; Gnudi, L.; Kahn, B.B. Amelioration of Insulin Resistance in Streptozotocin Diabetic Mice by Transgenic Overexpression of GLUT4 Driven by an Adipose-Specific Promoter 1. Endocrinology 1997, 138, 1604-1611. [CrossRef] [PubMed]

31. Farris, W.; Mansourian, S.; Chang, Y.; Lindsley, L.; Eckman, E.A.; Frosch, M.P.; Eckman, C.B.; Tanzi, R.E.; Selkoe, D.J.; Guénette, S. Insulin-degrading enzyme regulates the levels of insulin, amyloid $\beta$-protein, and the $\beta$-amyloid precursor protein intracellular domain in vivo. Proc. Natl. Acad. Sci. USA 2003, 100, 4162-4167. [CrossRef] [PubMed]

32. Abdul-Hay, S.O.; Kang, D.; McBride, M.; Li, L.; Zhao, J.; Leissring, M.A. Deletion of Insulin-Degrading Enzyme Elicits Antipodal, Age-Dependent Effects on Glucose and Insulin Tolerance. PLoS ONE 2011, 6, e20818. [CrossRef] [PubMed]

33. Abdul-Ghani, M.A. Contributions of beta-Cell Dysfunction and Insulin Resistance to the Pathogenesis of Impaired Glucose Tolerance and Impaired Fasting Glucose. Diabetes Care 2006, 29, 1130-1139. [CrossRef]

34. Wei, X.; Ke, B.; Zhao, Z.; Ye, X.; Gao, Z.; Ye, J. Regulation of insulin degrading enzyme activity by obesity-associated factors and pioglitazone in liver of diet-induced obese mice. PLoS ONE 2014, 9, e95399. [CrossRef] [PubMed]

35. Merino, B.; Fernández-Díaz, C.M.; Parrado-Fernández, C.; González-Casimiro, C.M.; Postigo-Casado, T.; Lobatón, C.D.; Leissring, M.A.; Cózar-Castellano, I.; Perdomo, G. Hepatic insulin-degrading enzyme regulates glucose and insulin homeostasis in diet-induced obese mice. Metabolism 2020, 113, 154352. [CrossRef]

36. Steneberg, P.; Bernardo, L.; Edfalk, S.; Lundberg, L.; Backlund, F.; Östenson, C.G.; Edlund, H. The type 2 diabetes-associated gene Ide is required for insulin secretion and suppression of $\alpha$-synuclein levels in $\beta$-cells. Diabetes 2013, 62, 2004-2014. [CrossRef]

37. Villa-Pérez, P.; Merino, B.; Fernández-Díaz, C.M.; Cidad, P.; Lobatón, C.D.; Moreno, A.; Muturi, H.T.; Ghadieh, H.E.; Najjar, S.M.; Leissring, M.A.; et al. Liver-specific ablation of insulin-degrading enzyme causes hepatic insulin resistance and glucose intolerance, without affecting insulin clearance in mice. Metabolism 2018, 88, 1-11. [CrossRef] 
38. Nagakura, T.; Yasuda, N.; Yamazaki, K.; Ikuta, H.; Tanaka, I. Enteroinsular axis of db/db mice and efficacy of dipeptidyl peptidase IV inhibition. Metabolism 2003, 52, 81-86. [CrossRef]

39. Mitchell, S.J.; Madrigal-Matute, J.; Scheibye-Knudsen, M.; Fang, E.; Aon, M.; González-Reyes, J.A.; Cortassa, S.; Kaushik, S.; Gonzalez-Freire, M.; Patel, B.; et al. Effects of Sex, Strain, and Energy Intake on Hallmarks of Aging in Mice. Cell Metab. 2016, 23, 1093-1112. [CrossRef] 